2

3

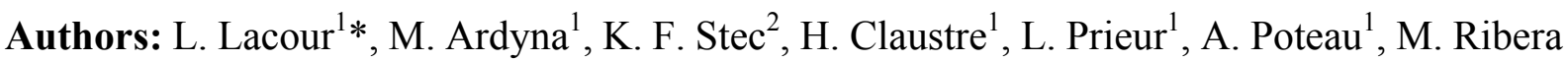
D’Alcala $^{2}$, D. Iudicone ${ }^{2}$

*Correspondence to: leo.lacour@obs-vlfr.fr.

\title{
Affiliations:
}

${ }^{1}$ Sorbonne Universités, UPMC Univ Paris 06, CNRS, Laboratoire d'Océanographie de Villefranche (LOV), Observatoire Océanologique, 06230 Villefranche-sur-Mer, France

${ }^{2}$ Laboratory of Ecology and Evolution of Plankton, Stazione Zoologica Anton Dohrn, Naples, Italy

Introductory paragraph: In mid- and high-latitude oceans, winter surface cooling and strong winds drive turbulent mixing that carries phytoplankton to depth of several hundred meters, well below the sunlit layer. This downward mixing, in combination with low solar radiation, drastically limits phytoplankton growth during the winter, especially that of the diatoms and other species that are involved in seeding the spring bloom. Here we present observational evidence for widespread winter phytoplankton blooms in a large part of the North Atlantic Subpolar Gyre from autonomous profiling floats equipped with biogeochemical sensors. These blooms were triggered by intermittent restratification of the mixed layer when mixed layer eddies led to a horizontal transport of lighter water over denser layers. Combining a bio-optical index with complementary chemotaxonomic and modelling approaches, we show that these restratification events increase phytoplankton residence time in the sunlight zone, resulting in greater light interception 
and the emergence of winter blooms. Restratification also caused a phytoplankton community shift from pico- and nanophytoplankton to phototrophic diatoms. We conclude that transient winter blooms can maintain active diatom populations throughout the winter months, directly seeding the spring bloom and potentially making a significant contribution to over-winter carbon export.

The Sverdrup paradigm ${ }^{1}$ postulates that deep winter mixing prevents phytoplankton biomass accumulation since losses exceed light-limited production. However, few wintertime in situ observations revealed significant phytoplankton stock in deep mixed layers ${ }^{2,3}$. Based on modelling simulations, orbital motions triggered by deep convection have been suggested to allow recurrent incursions of phytoplankton to the surface lit layer, and thus supporting a winter production ${ }^{4}$. Furthermore, winter deepening of the mixed layer would dilute plankton concentration, thus reducing grazing pressure, and consequently, phytoplankton loss (disturbance-recovery hypothesis) ${ }^{5,6}$. Despite low phytoplankton growth, biomass may accumulate throughout winter in deep mixed layers.

Modelling studies have shown that mixed layer eddies (MLEs) growing from horizontal density gradients can generate vertical restratification of the mixed layer at spatial scales of 1$10 \mathrm{~km}$ and time scales of days ${ }^{7,8}$, thus allowing patchy blooms to be initiated before the vernal stratification ${ }^{9}$. MLEs being potentially much more frequent in winter ${ }^{10}$, such restratification mechanism may provide an additional mechanism for winter phytoplankton growth.

In addition, other studies have proposed that a reduction in turbulent mixing, due to a relaxation in atmospheric forcing, may allow phytoplankton to grow, before the vernal restratification (critical turbulence hypothesis) ${ }^{11-13}$. 
In this context, distinguishing the mixing layer depth from the mixed layer depth is important when dealing with phytoplankton dynamics ${ }^{14-16}$. In the following, we improved the determination of the mixed layer depth to be the closest to the mixing layer depth (see Supplementary Methods 1.4) given that there are no large scale, autonomous measurements of turbulence so far.

\section{Winter mixing intermittency}

The common view is that the North Atlantic subpolar ocean is continuously deeply mixed during winter ${ }^{17,18}$. However, around $25 \%$ of Argo density profiles in this area were stratified (mixed layer depth (MLD) < $100 \mathrm{~m}$, Supplementary Methods 1.4) during the winters of 2014 and 2015 (Fig. 1a and Supplementary Fig. 4). The vertical stratification was particularly strong in areas of significant horizontal density gradients (Fig. 1b), suggesting the potential role of MLEs. MLEs drive net horizontal transfer of lighter water above heavier water that can locally stratify the mixed layer. Similar temperature and salinity structure (i.e. Turner angle ${ }^{19}$ ) between horizontal and vertical density gradients in the subpolar gyre (Fig. 1c, Supplementary Methods 1.3) confirm the crucial role of lateral processes in restratifying the deep winter mixed layer in the North Atlantic Subpolar Gyre.

Restratification mechanisms compete with vertical mixing induced mainly by surface wind and cooling ${ }^{9}$. Thus, restratification events require sufficiently long calm periods with a relaxation of this atmospheric forcing. While analysing wind speed and heat fluxes, we observed that some regions of the subpolar gyre presented up to $30 \%$ of calm periods (Fig. $1 \mathrm{~d}$, Supplementary Fig. 5 and Methods 1.6). A proxy of the sea state (i.e. wave height, Supplementary Methods 1.7), derived from BGC-Argo floats, also confirmed evidence of calm periods (i.e. $20 \%$ of the winter profiles, Supplementary Fig. 7). Therefore, transient calm periods appear to be frequent across the North Atlantic Subpolar Gyre, allowing restratification to be a recurrent feature in winter. 


\section{Mixing intermittency triggers winter phytoplankton blooms}

Restratification events triggered winter phytoplankton accumulations in the surface layer in the whole subpolar gyre (based on two different proxies of phytoplankton biomass: chlorophyll $a$ (chla) and particulate optical backscattering ( $\left.b_{\mathrm{bp}}\right)$; Fig. 2 and Supplementary Fig. 9). These restratification events maintain phytoplankton cells in the euphotic zone (surface to Ze; see Fig. 2b and Supplementary Fig. 15), enhancing the light availability for their growth. Indeed, the light level (i.e. the daily-integrated Photosynthetically Available Radiation (PAR) averaged over the MLD) increased ten-fold in average in stratified conditions (MLD $<100 \mathrm{~m}$; $1.3 \mathrm{~mol}$ photons $\mathrm{m}^{-2}$ ) compared to deeply mixed conditions (MLD > $100 \mathrm{~m} ; 0.13 \mathrm{~mol}$ photons $\mathrm{m}^{-2}$ ). For $70 \%$ of the stratified profiles (Fig. $2 \mathrm{~b}$, top panel), an increase in light exposure led to the occurrence of winter blooms, defined here as a biomass increase of $5 \%$ above the winter median value $\left(75 \%\right.$ of the stratified profiles using $b_{b p}$ instead of chla). These observations suggest that most of the calm periods lasted long enough to initiate locally transient winter phytoplankton blooms.

Importantly, distinct light environments between stratified and deeply mixed conditions impacted not only phytoplankton production but also the structure of the community ${ }^{20,21}$. An optical community index (chla to $b_{b p}$ ratio ${ }^{22}$ ) derived from BGC-Argo float measurements, revealed a clear shift in the phytoplankton community structure during restratification events. In typical winter conditions (i.e., deep mixed layers with low surface daily-integrated PAR), pico- and nanophytoplankton clearly dominated the overall phytoplankton community in the subpolar gyre (Fig. 3a). By contrast, the proportion of diatoms temporarily increases during transient restratification events when their growth was evidently boosted by more favourable light conditions (Fig. 3a, b). These blooms became particularly frequent in late February and March (10-25\% of the all profiles, $n=30$, Fig. 3b), when frequency of restratification events 
increased $(20-40 \%$ of the all profiles, $\mathrm{n}=86 ; \mathrm{r}=0.94$, $\mathrm{p}$-value $<0.01)$ and surface dailyintegrated PAR was higher due to longer daylength (Fig. 3c). Variation of the cloudiness (dot size in Fig. 3c) also reinforced the critical role of light level, and its impact on changing the community composition in winter. During calm periods with clear sky conditions, higher surface daily-integrated PAR significantly boosted the growth of diatoms (Fig. 3c; $r=0.56$, pvalue $<0.01$, see supplementary Table.3). These findings have been corroborated by rare phytoplankton pigment samples collected during a winter cruise in the Newfoundland Basin (CATCH, January-February 1997, Fig. 2a and Supplementary Methods 1.10 and 2.5). While deep mixing layers were dominated by chryso- and pelagophytes, contributing to almost $50 \%$ of the total chla, diatoms became a relevant group contributing to almost $20 \%$ of the total chla when MLD shoaled above 100 m (Supplementary Fig. 16).

\section{Reassessing the winter as an active phytoplankton period}

Moderate to high light-adapted diatoms thriving in spring are not likely able to survive in deep winter mixed layers. A set of suitable overwintering strategies, e.g. formation of resting cells or spores ${ }^{23,24}$, have been highlighted as means to survive harsh winter conditions. Here, we show that diatoms can remain physiologically active throughout winter by benefiting from transient restratification events and thus more favourable light environments (Supplementary Fig. 17 and 19). By contrast, the persistence of pico- and nanophytoplankton, especially small flagellates, and their dominance in deep mixing layers may be explained by mixotrophy, the combined used of phototrophy and heterotrophy within a single organism ${ }^{25}$. The shift to heterotrophy during long period of darkness at depth could confer to these organisms a serious ecological advantage and bring an alternative hypothesis to the disturbance-recovery hypothesis 5. 
An extraordinary number of studies emerged during the last decade to understand the dynamics of the high-latitude spring bloom (i.e. timing and magnitude). However, the vigorous debate on spring bloom dynamics has remained mainly focused on physical controls of phytoplankton biomass accumulation. Our observations reveal that the physical environment plays a key role also in shaping the community structure during the preconditioning period of the spring bloom. Although transient winter blooms, supported by mixing intermittency, are not intense in term of biomass, they maintain an active diatom population throughout winter. Unlike resting cells or spores that require a germination period ${ }^{26}$, active winter diatoms can directly seed the spring bloom, hence impacting the bloom timing and potentially its magnitude.

\section{Implications for spring bloom and carbon export dynamics}

Results of a parallel subpolar phytoplankton community model (Supplementary Methods 2.7) support the claim that intermittent winter stratification can affect spring bloom characteristics. Restratification events in winter boost diatom net growth rate (Supplementary Fig. 17), increasing the standing stock of diatoms towards spring. Mixing intermittency may increase by up to 2 fold the bloom magnitude and bring the bloom peak timing forward by up to 19 days (Supplementary Fig. 19 and Table 7). These results not only corroborate in situ observations (i.e. BGC-Argo and CATCH data) but further suggest a possible impact of winter mixing intermittency on the observed yet unexplained ${ }^{27}$ interannual variability of spring blooms.

Unexpected wintertime occurrence of diatom blooms in the subpolar gyre could also challenge our perception of the spring bloom-dependent carbon export. Alternation of stratification and deep mixing allows transient diatom blooms along with non-sinking particles and dissolved organic and inorganic carbon to be transferred rapidly to depth (the so-called 
145 mixed layer pump ${ }^{28-30}$ ). Even though a single event transfers only a low carbon stock compared 146 to the spring bloom, cumulative events over the winter months may contribute significantly to 147 the annual carbon export.

Methods

Methods and supplementary figures are available in the supplementary information.

Data availability

152

153

154

155

156

157

158

159

160

161

162

163

164

165

166

Argo data were collected and made freely available by the International Argo Program and the CORIOLIS project that contribute to it (http://www.coriolis.eu.org). BGC-Argo data are publicly available at ftp://ftp.ifremer.fr/ifremer/argo/dac/coriolis/. Net heat flux and wind data were extracted from the ECMWF ERA Interim dataset (reanalysis) freely available at http://apps.ecmwf.int/datasets/data/interim-full-daily/levtype=sfc. The MLD climatology was provided by Ifremer (http://www.ifremer.fr/cerweb/deboyer/mld/home.php).

\section{References}

1. Sverdrup, H. U. On conditions for the vernal blooming of phytoplankton. J. $d u$ Cons. Int. pour l'exploitation la mer 18, 287-295 (1953).

2. Backhaus, J. O. et al. Convecion and primary production in winter. Mar. Ecol. Progr. Ser. 251, 1-14 (2003).

3. Dale, T., Rey, F. \& Heimdal, B. R. Seasonal development of phytoplankton at a high latitude oceanic site. Sarsia 84, 419-435 (1999).

4. Große, F., Lindemann, C., Pätsch, J. \& Backhaus, J. O. The influence of winter 
convection on primary production: A parameterisation using a hydrostatic threedimensional biogeochemical model. J. Mar. Syst. 147, 138-152 (2015).

5. Behrenfeld, M. J. Abandoning Sverdrup's Critical Depth Hypothesis on phytoplankton blooms. Ecology 91, 977-989 (2010).

6. Behrenfeld, M. J., Doney, S. C., Lima, I., Boss, E. S. \& Siegel, D. A. Annual cycles of ecological disturbance and recovery underlying the subarctic Atlantic spring plankton bloom. Global Biogeochem. Cycles 27, 526-540 (2013).

7. Boccaletti, G., Ferrari, R. \& Fox-Kemper, B. Mixed Layer Instabilities and Restratification. J. Phys. Oceanogr. 37, 2228-2250 (2007).

8. Fox-Kemper, B., Ferrari, R. \& Hallberg, R. Parameterization of Mixed Layer Eddies. Part I: Theory and Diagnosis. J. Phys. Oceanogr. 38, 1145-1165 (2008).

9. Mahadevan, a., D’Asaro, E., Lee, C. \& Perry, M. J. Eddy-Driven Stratification Initiates North Atlantic Spring Phytoplankton Blooms. Science (80-. ). 337, 54-58 (2012).

10. Callies, J., Ferrari, R., Klymak, J. M. \& Gula, J. Seasonality in submesoscale turbulence. Nat. Commun. 6, 6862 (2015).

11. Huisman, J. \& Weissing, F. J. Biodiversity of plankton by species oscillations and chaos. Nature 402, 407-410 (1999).

12. Taylor, J. R. \& Ferrari, R. Shutdown of turbulent convection as a new criterion for the onset of spring phytoplankton blooms. Limnol. Ocean. 56(6), 2293-2307 (2011).

13. Ferrari, R., Merrifield, S. T. \& Taylor, J. R. Shutdown of convection triggers increase of surface chlorophyll. J. Mar. Syst. 147, 116-122 (2015). 
14. Brainerd, K. E. \& Gregg, M. C. Surface mixed and mixing layer depths. Deep. Res. Part I 42, 1521-1543 (1995).

15. Franks, P. J. S. Has Sverdrup's critical depth hypothesis been tested? Mixed layers vs. turbulent layers. ICES J. Mar. Sci. 72, 1897-1907 (2015).

16. Brody, S. R. \& Lozier, M. S. Changes in dominant mixing length scales as a driver of subpolar phytoplankton bloom initiation in the North Atlantic. Geophys. Res. Lett. 41, 3197-3203 (2014).

17. Behrenfeld, M. J. \& Boss, E. S. Resurrecting the ecological underpinnings of ocean plankton blooms. Ann. Rev. Mar. Sci. 6, 167-194 (2014).

18. Lindemann, C. \& St. John, M. A. A seasonal diary of phytoplankton in the North Atlantic. Front. Mar. Sci. 1, 37 (2014).

19. Johnson, L., Lee, C. M. \& D’Asaro, E. A. Global Estimates of Lateral Springtime Restratification. J. Phys. Oceanogr. 46, 1555-1573 (2016).

20. Litchman, E. Growth rates of phytoplankton under fluctuating light. Freshw. Biol. 44, $223-235$ (2000).

21. Walter, B., Peters, J., Van Beusekom, J. E. E. \& St. John, M. A. Interactive effects of temperature and light during deep convection: A case study on growth and condition of the diatom Thalassiosira weissflogii. ICES J. Mar. Sci. 72, 2061-2071 (2015).

22. Cetinić, I. et al. A simple optical index shows spatial and temporal heterogeneity in phytoplankton community composition during the 2008 North Atlantic Bloom Experiment. Biogeosciences 12, 2179-2194 (2015).

23. Smetacek, V. S. Role of sinking in diatom life-history cycles: ecological, evolutionary and geological significance. Mar. Biol. 84, 239-251 (1985). 
24. McQuoid, M. R. \& Hobson, L. A. Diatom resting stages. J. Phycol. 32, 889-902 (1996).

25. Caron, D. A. Mixotrophy stirs up our understanding of marine food webs. Proc. Natl. Acad. Sci. U. S. A. 113, 2806-2808 (2016).

26. Smayda, T. J. \& Mitchell-Innes, B. Dark survival of autotrophic, planktonic marine diatoms. Mar. Biol. 25, 195-202 (1974).

27. Barton, A. D., Lozier, M. S. \& Williams, R. G. Physical controls of variability in North Atlantic phytoplankton communities. Limnol. Oceanogr. 60, 181-197 (2014).

28. Gardner, W. D., Chung, S. P., Richardson, M. J. \& Walsh, I. D. The oceanic mixedlayer pump. Deep Sea Res. Part II Top. Stud. Oceanogr. 42, 757-775 (1995).

29. Dall'Olmo, G. \& Mork, K. A. Carbon export by small particles in the Norwegian Sea. Geophys. Res. Lett. 41, 2921-2927 (2014).

30. Koeve, W., Pollehne, F., Oschlies, A. \& Zeitzschel, B. Storm-induced convective export of organic matter during spring in the northeast Atlantic Ocean. Deep. Res. Part I Oceanogr. Res. Pap. 49, 1431-1444 (2002).

\section{Corresponding author}

Correspondence and requests for materials should be addressed to L.L. (leo.lacour@obs-vlfr.fr)

\section{Acknowledgements}

We thank N. Briggs, M. J. Perry, E. D’Asaro, B. Gentili, E. Boss and F. Benedetti for fruitful discussions, C. Schmechtig for BGC-Argo float data management and Joséphine Ras for 
proofreading the manuscript. We also thank Simon Wright for sharing the CHEMTAX software

235 v.1.95, and Clément de Boyer Montégut for providing the MLD climatology. This work represents a contribution to the remOcean project (REMotely sensed biogeochemical cycles in

237 the OCEAN, GA 246777) funded by the European Research Council, the ATLANTOS EU 238 project (grant agreement 2014-633211) funded by H2020 program and the Italian Flagship 239 Program RITMARE.

\section{Author contributions}

242 D.I. and L.L. designed the study. L.L., M.A., K.F.S., H.C., A.P., M.R.D. and D.I. conducted 243 the data analysis. L.L. and M.A. wrote the manuscript. All authors commented on the 244 manuscript.

246 Competing financial interests

247 The authors declare no competing financial interests. 
a

C
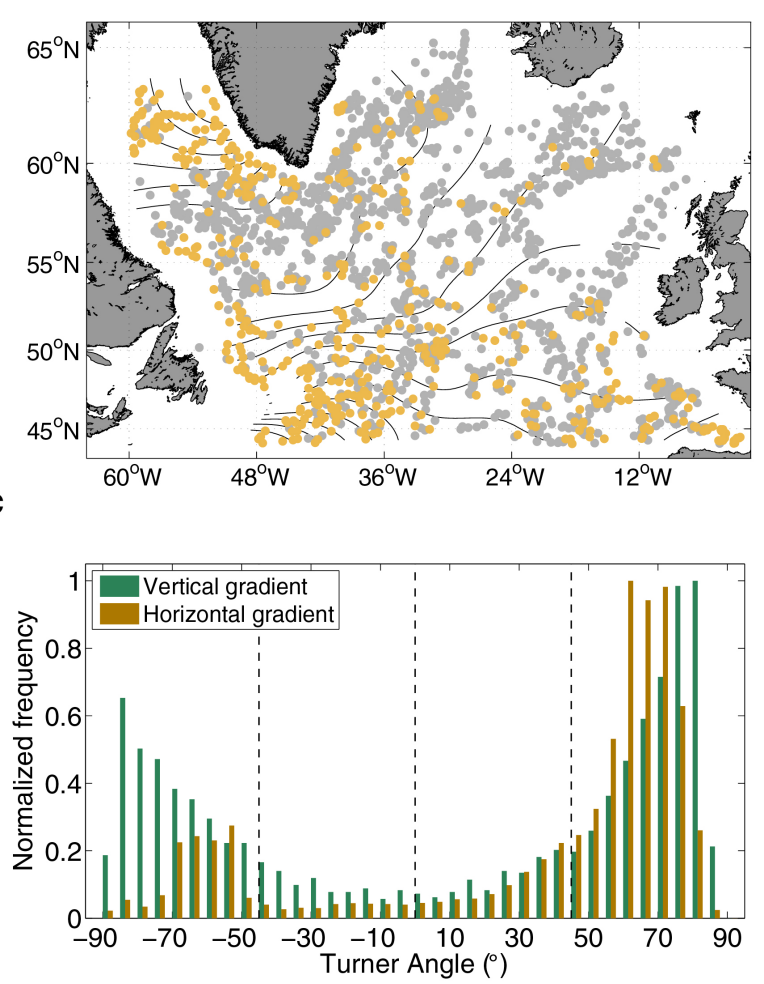

b
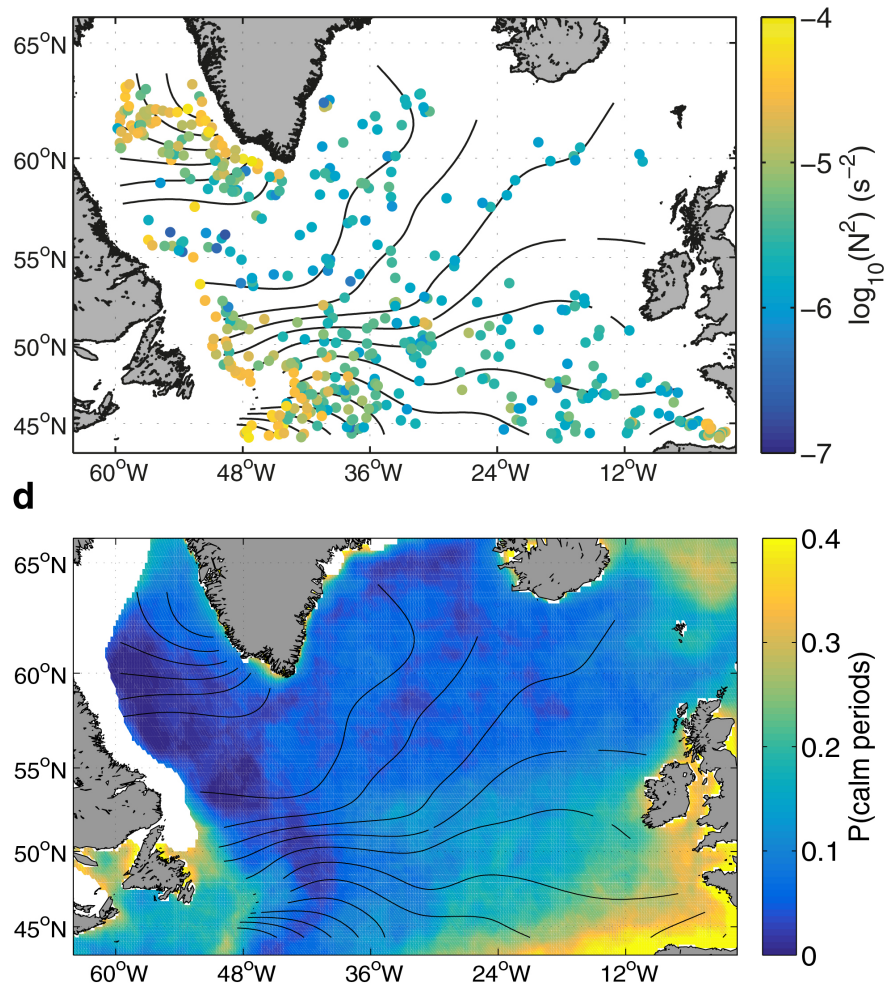

249 Fig. 1. Winter mixing intermittency in the North Atlantic Subpolar Gyre. (a) 2022 Argo float 250 profiles (January-March 2014-2015). Orange dots mark the location of stratified profiles (MLD $<100 \mathrm{~m}$ ) and grey dots mark the deep mixed profiles (MLD > $100 \mathrm{~m}$ ). (b) Stratification intensity (average value of $\mathrm{N}^{2}$ between 5 and $100 \mathrm{~m}$ ) of profiles with MLD $<100 \mathrm{~m}$. (c)

253 Frequency distribution of Turner angle for horizontal (orange) and vertical (green) density 254 gradients. Each distribution is normalized by its maximum frequency. Vertical dashed lines 255 mark angle $0^{\circ}$, where both temperature and salinity contribute equally to the density gradient, and angle $-45^{\circ}$ and $45^{\circ}$ where salinity and temperature respectively are the only contributor.

257 Angles $>45^{\circ}$ or $<-45^{\circ}$ indicate that salinity is working against temperature and vice versa. (d)

258 Probability to have calm periods lasting at least 24 hours during January-March 2014-2015. A 259 calm period is defined as a $>24$ hour period with wind speed $<10 \mathrm{~m} \mathrm{~s}^{-1}$ and net heat flux $>$ $260100 \mathrm{~W} \mathrm{~m}^{-2}$. White pixels indicate the presence of sea ice (Supplementary Methods 1.2). Black 
261 lines in (a), (b) and (d) denote contours of surface density (contour interval of $0.1 \mathrm{~kg} \mathrm{~m}^{-3}$, 262 maximum and minimum density of 27.74 and $25.90 \mathrm{~kg} \mathrm{~m}^{-3}$ respectively). 

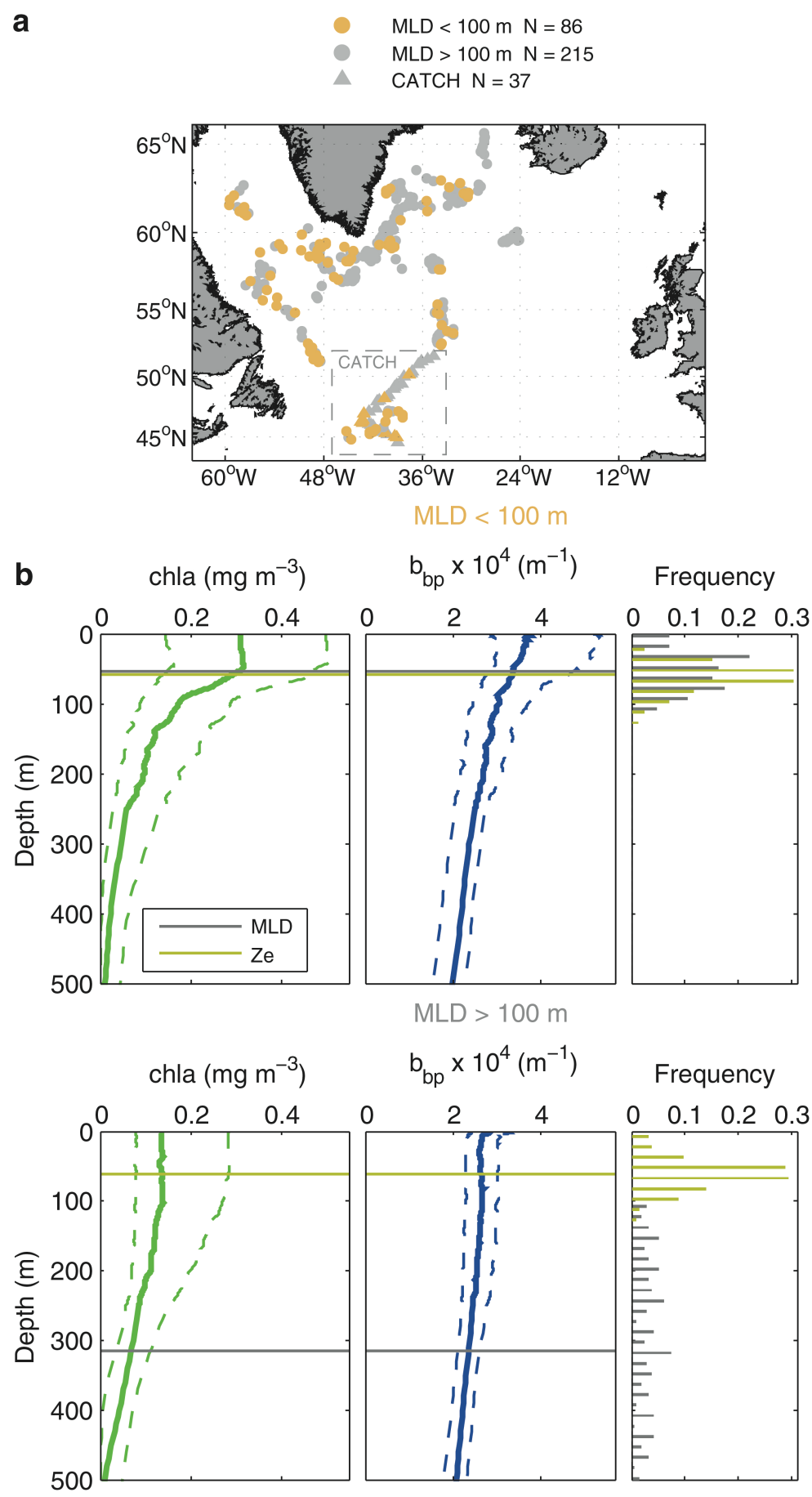

264 Fig. 2. Winter phytoplankton blooms in the North Atlantic Subpolar Gyre. (a) Location of the 265301 BGC-Argo float profiles (dots, January-March 2014-2015) and the 37 pigment profiles 266 from the CATCH cruise (triangles, January-February 1997). Orange symbols indicate stratified 267 profiles (MLD $<100 \mathrm{~m}, 35 \%$ of the profiles, including CATCH profiles) and grey symbols 268 indicate deep mixed profiles (MLD $>100 \mathrm{~m})$. The dashed rectangle delineates the study area 
269 for the CATCH expedition. (b) Median profile and quartiles of chlorophyll $a$ (chla) and 270 backscattering $\left(\mathrm{b}_{\mathrm{bp}}\right.$ ) from BGC-Argo floats shown in (a), for MLD < $100 \mathrm{~m}$ (top) and MLD > $271100 \mathrm{~m}$ (bottom). The two sets of data (MLD $<100 \mathrm{~m}$ and MLD $>100 \mathrm{~m}$ ) are statistically 272 different in term of both surface chla and $b_{b p}$ (Wilcoxon test, $p$-value $<0.01$ ). Every single chla 273 and $b_{b p}$ profile is shown in Supplementary Fig. 9. Horizontal grey and yellow lines indicate the 274 median MLD and euphotic depth (Ze) respectively. Ze is defined as the depth of the 0.1 mol 275 photons $\mathrm{m}^{-2}$ daily isolume (Supplementary Methods 1.8). Panels on the right show the 276 frequency distribution of MLD (grey) and euphotic depth (yellow). 

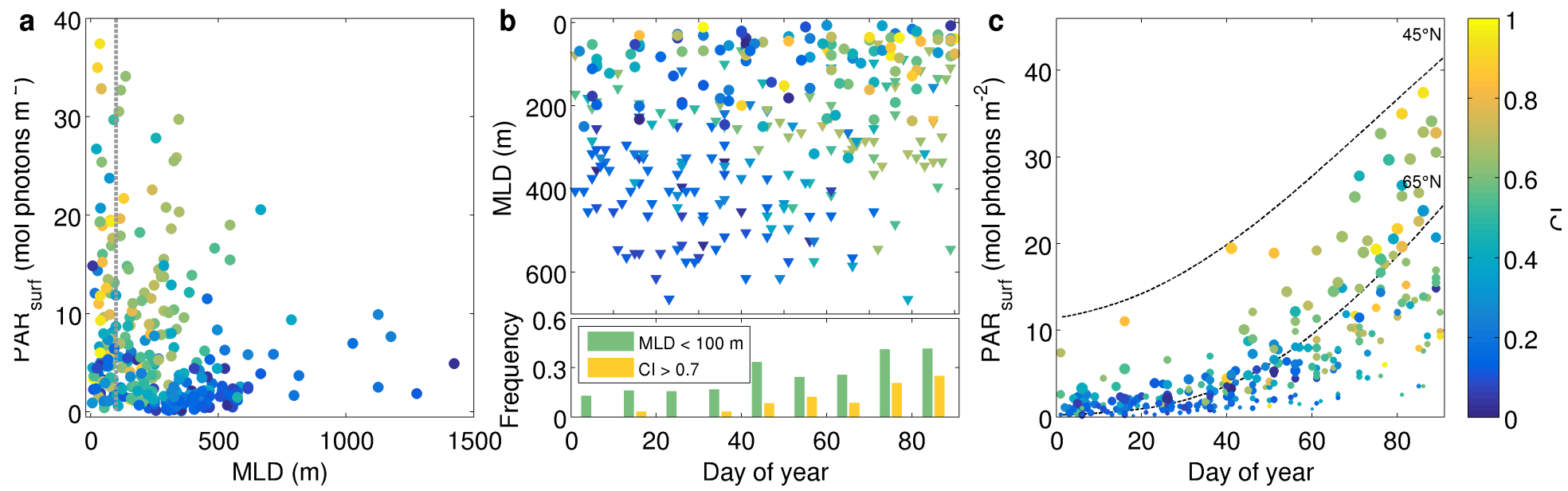

277

278 Fig. 3. The light environment impacts the phytoplankton community structure. Colour scale

279 denotes the optical community index CI (normalized chlorophyll $a$ to backscattering ratio). CI

280 close to 1 indicates a large contribution of diatoms to the community whereas CI close to 0

281 indicates a pico- and nanophytoplankton-dominated community (Supplementary Methods 1.9).

282 (a) Surface daily-integrated photosynthetically available radiation (PAR) and MLD derived

283 from all BGC-Argo float profiles shown in Fig. 2a. Vertical dashed grey line marks $100 \mathrm{~m}$

284 depth. (b) MLD as function of day of year (from $1^{\text {st }}$ January to 31 March, top). Circles and

285 triangles represent positive and negative MLD anomalies respectively (i.e. deviation from the

286 climatological seasonal cycle, supplementary Methods 2.2). Frequency of stratified profiles

287 (MLD $<100 \mathrm{~m}$ ) and frequency of profiles with $\mathrm{CI}>0.7$ over a ten days period (bottom). (c)

288 Surface daily-integrated PAR as function of day of year. Dot size denotes the cloudiness (large

289 for clear sky and small for dark sky). Dashed black lines indicate temporal evolution of

290 modelled clear sky surface PAR for the minimum and maximum latitudes of the domain $\left(45^{\circ} \mathrm{N}\right.$

291 and $\left.65^{\circ} \mathrm{N}\right)$. 